\title{
L-Arginine Exacerbates Experimental Cerebral Malaria by Enhancing Pro-Inflammatory Responses
}

\author{
Hongbin Xu, ${ }^{1}$ Yonghui Feng, ${ }^{2}$ Guang Chen ${ }^{3}$ Xiaotong Zhu, ${ }^{1}$ Wei Pang, ${ }^{1}$ \\ Yunting Du, ${ }^{1}$ Qinghui Wang, ${ }^{1}$ Zanmei Qi ${ }^{1}$ and Yaming Cao ${ }^{1}$

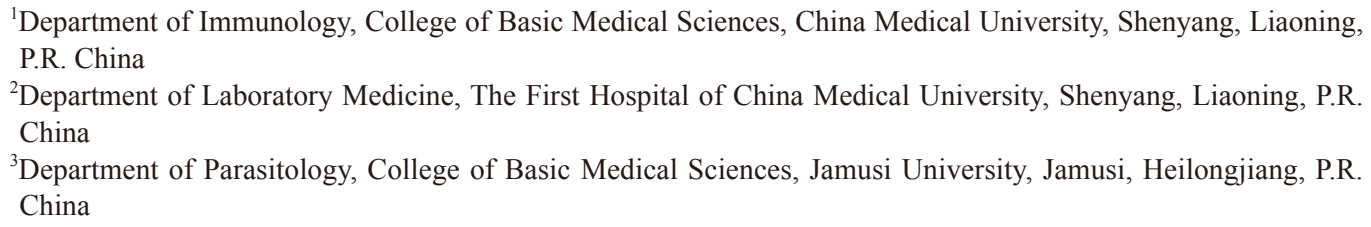

L-Arginine (L-Arg), the substrate for nitric oxide (NO) synthase, has been used to treat malaria to reverse endothelial dysfunction in adults. However, the safety and efficacy of L-Arg remains unknown in malaria patients under the age of five, who are at the greatest risk of developing cerebral malaria (CM), a severe malaria complication. Here, we tested effects of L-Arg treatment on the outcomes of CM using a mouse model. Experimental cerebral malaria (ECM) was induced in female C57BL/6 mice infected with Plasmodium berghei ANKA, and L-Arg was administrated either prophylactically or after parasite infection. Surprisingly, both types of L-Arg administration caused a decline in survival time and raised CM clinical scores. L-Arg treatment increased the population of CD4 ${ }^{+} \mathrm{T}-\mathrm{bet}^{+} \mathrm{IFN}-\gamma^{+}$Th1 cells and the activated macrophages $\left(\mathrm{F} 4 / 80^{+} \mathrm{CD} 36^{+}\right)$in the spleen. The levels of pro-inflammatory cytokines, IFN- $y$ and TNF- $\alpha$, in splenocyte cultures were also increased by L-Arg treatment. The above changes were accompanied with a rise in the number of dendritic cells (DCs) and an increase in their maturation. However, L-Arg did not affect the population of regulatory $\mathrm{T}$ cells or the level of IL-10 in the spleen. Taken together, these data suggest that L-Arg may enhance the Th1 immune response, which is essential for a protective response in uncomplicated malaria but could be lethal in CM patients. Therefore, the prophylactic use of L-Arg to treat $\mathrm{CM}$, based on the assumption that restoring the bioavailability of endothelial NO improves the outcome of $\mathrm{CM}$, may need to be reconsidered especially for children.

Keywords: dendritic cells; L-Arginine; malaria; regulatory T cell; Th1 immune responses Tohoku J. Exp. Med., 2015 May, 236 (1), 21-31. C 2015 Tohoku University Medical Press

\section{Introduction}

Malaria, a mosquito borne parasite infection, is caused by several species of the genus Plasmodium ( $P$.): P. falciparum, $P$. vivax, $P$. ovale, $P$. malariae, and $P$. knowlesi. According to the WHO world malaria report from 2013 (World Health Organization 2013), there were 207 million cases and 627,000 malaria deaths estimated globally in 2012. Infection with P. falciparum causes severe and sometimes fatal symptoms characterized by cerebral malaria (CM), multi-organ dysfunction, and non-cerebral severe malaria (NCSM) (Gupta et al. 1999; Walton et al. 2014). $\mathrm{CM}$ is one of the most severe complications and is a major cause of death after $P$. falciparum infection.

The host immune response significantly influences the outcome of malaria infection. An excessive immune response can result in immunopathology. It is generally accepted that $\mathrm{CM}$ results from a combination of sequestering infected red blood cells in the cerebral blood vessels and a vigorous host pro-inflammatory response mediated by cytokines and effector cells (Hearn et al. 2000; Belnoue et al. 2002; Nitcheu et al. 2003; Franke-Fayard et al. 2005; Pais and Chatterjee 2005). The failure to establish a balance between the pro- and anti-inflammatory immune responses is likely one of the underlying causes of severe malaria (Walther et al. 2009). Therefore, an appropriate and effective immune response during malaria infection is essential for the host to eliminate this pathogen without causing additional damage.

Th1 cytokines play a critical role in controlling the early phase of malaria infection, but they are also associated with developing CM (Engwerda et al. 2005; Nie et al. 2007). A great deal of evidence about the inflammatory processes that contribute to the development of $\mathrm{CM}$ has

Received November 27, 2014; revised and accepted April 3, 2015. Published online April 29, 2015; doi: 10.1620/tjem.236.21.

Correspondence: Yaming Cao, Department of Immunology, College of Basic Medical Sciences, China Medical University, No. 77

$\mathrm{Pu}$ He Road, Shen Bei Xin District, Shenyang, Liaoning 1100122, P.R. China.

e-mail: ymcao@mail.cmu.edu.cn 
been provided by the Plasmodium berghei ANKA ( $P b$ ANKA) model (de Souza and Riley 2002; Miller et al. 2002; Schofield and Grau 2005; Hansen 2012). We have previously shown that regulatory $\mathrm{T}$ cells (Treg) prevent the development of $\mathrm{CM}$ by modifying the pro-inflammatory response in $P b$ ANKA-infected C57BL/6 mice (Wu et al. 2010).

L-Arginine (L-Arg) is considered an essential amino acid for infants, but not for adults. Recent studies suggested that L-Arg is crucial for the function of host immune cells. L-Arg deprivation induces $\mathrm{T}$ cell hypo-responsiveness, defined as a profound reduction in $\mathrm{T}$ cell proliferation and reduced $\mathrm{CD} 3 \zeta$ chain expression (Rodriguez et al. 2002, 2003; Zea et al. 2004, 2005; Kropf et al. 2007). L-Arg deficiency is also correlated with a dramatic reduction in B-cell maturation and a significant decrease in serum IgM, due to an impaired transition from pro- to pre-B cells (de Jonge et al. 2002). Macrophage activation is also dependent on L-Arg (Yeramian et al. 2006), which suggests L-Arg might contribute to the production of nitric oxide (NO). Abnormal NO production is believed to play a significant role in the pathogenesis of severe malaria (Yeo et al. 2008a). Low serum levels of NO have been reported in individuals with malaria, and the lowest levels observed in children who died from CM (Anstey et al. 1996). L-Arg, the substrate for NO synthase, has been used to treat malaria. Phase I trials have shown that L-Arg is safe and well tolerated in adults with moderate-to-severe malaria, and arginine infusion has been associated improving NO bioavailability leading to recovery of endothelial function (Yeo et al. 2008a). However, little is known about the safety and efficacy of L-Arg supplementation in malaria patients under the age of five who are considered to have the greatest risk of developing severe malaria complications, like CM.

To further characterize the role of L-Arg in developing $\mathrm{CM}$, we examined the production of pro-inflammatory cytokines and changes to the functions of effector cells including $\mathrm{T}$ cells, macrophages, and dendritic cells (DCs) in an experimental CM model supplemented with L-Arg. We demonstrated that, although L-Arg treatment increased NO production, it also enhanced the Th1 pro-inflammatory immune response, leading to accelerated CM development. Our findings suggest that prophylactic strategies based on NO restoration to improve the outcome of experimental $\mathrm{CM}$ may be more complicated than originally envisioned.

\section{Materials and Methods}

Mice, parasites, and experimental infection

Female 6-8-week-old C57BL/6 mice were purchased from the Center of Zoology, Chinese Academy of Sciences (Shanghai branch). $\mathrm{Pb}$ ANKA was kindly provided by Dr. Motomi Torii (Department of Molecular Parasitology, Ehime University Graduate School of Medicine, Ehime, Japan). Mice were infected by intraperitoneal (i.p.) injection of $1 \times 10^{6} \mathrm{~Pb}$ ANKA parasitized erythrocytes from C57BL/6 mice. Parasitemia was monitored by examining Giemsa-stained, thin (tail) blood smears under a light microscope (Slade and Langhorne
1989). Mortality was monitored daily. A clinical experimental cerebral malaria (ECM) score was defined based on the presence of the following signs: ruffled fur, hunching, wobbly gait, limb paralysis, convulsions, and coma. For each sign present the mouse was given a score of 1 . Animals with scores $\geq 4$ were considered to have severe ECM. Animal experiments in this study were approved by the Animal Ethics Committee of China Medical University.

\section{L-Arg treatment}

L-Arg was purchased from Sigma-Aldrich (St. Louis, MO, USA) and dissolved in normal saline before use. L-Arg $(1.5 \mathrm{mg} / \mathrm{g})$ was given orally to two groups of mice either before (Pre-L-Arg) or after $\mathrm{Pb}$ ANKA infection (Pro-L-Arg). In the Pre-L-Arg group, mice received L-Arg once a day for seven days until they were infected with malaria parasites. While in the Pro-L-Arg group, L-Arg was administrated from the day of malaria infection until the mice died or were cured. An equivalent volume of normal saline was used for the control group.

\section{Splenocyte preparation and culture}

Splenocyte culture was performed as previously described (Wang et al. 2009). Briefly, the spleens from normal and infected mice were removed aseptically and pressed through a sterile fine-wire mesh with $10 \mathrm{~mL}$ of RPMI 1640 supplemented with $10 \%$ heat-inactivated fetal calf serum, $25 \mathrm{mM}$ Hepes, $0.12 \%$ gentamicin, and $2 \mathrm{mM}$ glutamine. The resulting cell suspensions were pelleted by centrifuging at $350 \mathrm{~g}$ for $10 \mathrm{~min}$. The erythrocytes in the splenocyte suspension were lysed with cold $0.17 \mathrm{M} \mathrm{NH}_{4} \mathrm{Cl}$ and the remaining cells were washed twice with fresh medium. After the erythrocytes had been lysed, the splenocytes were cultured ( $500 \mu \mathrm{L} /$ well) into 24 -well flatbottom tissue culture plates (Falcon) in triplicate and incubated for 48 $\mathrm{h}$ at $37^{\circ} \mathrm{C}$ in a humidified $5 \% \mathrm{CO}_{2}$ incubator. The supernatants were collected and stored at $-80^{\circ} \mathrm{C}$ until they were used to detect cytokines and NO levels.

\section{Flow cytometry analysis}

Mice were sacrificed at the indicated time points after infection and splenocytes were isolated for flow cytometry analysis. The viability of the cells was determined by Trypan blue exclusion test and only samples with viability $>98 \%$ were use for further staining. The subsets of spleen cells were defined as: $\mathrm{CD} 11 \mathrm{c}^{+} \mathrm{CD} 11 \mathrm{~b}^{+}$myeloid DCs, $\mathrm{CD} 11 \mathrm{c}^{+} \mathrm{CD} 45 \mathrm{R} / \mathrm{B} 220^{+}$plasmacytoid DCs, F4 $/ 80^{+} \mathrm{CD} 36^{+}$macrophages, CD4 ${ }^{+} \mathrm{T}-$ bet $^{+} \mathrm{IFN}-\gamma^{+} \mathrm{T}$ cells, and $\mathrm{CD} 4^{+} \mathrm{CD} 25^{+} \mathrm{Foxp}^{+}$Treg. Mature CD11 $\mathrm{c}^{+} \mathrm{DCs}$ were identified by the expression of MHCII, CD86, and TLR9. Unless otherwise indicated, antibodies were purchased from BD Pharmingen. The following antibodies were used: FITC-conjugated anti-CD11c (clone HL-3), PE-conjugated antiCD11b (clone M1/70), PerCP-conjugated anti-B220 (clone RA36B2), PE-conjugated anti-MHCII (clone M5/114.15.2), PEconjugated anti-CD86 (clone GL1), biotinylated anti-TLR9 (clone 5G5, purchased from Hycult biotech), PE-conjugated streptavidin (purchased from Biolegend), APC-conjugated anti-IFN- $\gamma$ (XMG1.2), FITC-conjugated anti-F4/80 (clone BMB), PE-conjugated anti-CD36 (clone 72-1, purchased from eBioscience), FITC-conjugated antiCD4 (clone GK1.5), anti-T-bet-PE (clone eBio4B10, purchased from eBioscience), PE-conjugated anti-CD25 (clone PC61), and APCconjugated anti-Foxp3 (clone FJK16s, purchased from eBioscience). 


\section{Intracellular staining}

To measure the intracellular level of IFN- $\gamma, 1 \times 10^{7}$ fresh splenocytes were stimulated in 12 -well plates with phorbol myristate acetate $(50 \mathrm{ng} / \mathrm{mL})$ and ionomycin $(0.5 \mu \mathrm{g} / \mathrm{mL})$. After 2 hours, Golgi stop $(2 \mu \mathrm{M})$ was added to block cytokine export. After an additional 4 hours of incubation ( 6 hours total), the cells were surface strained with anti-CD4-FITC. The cells were then fixed, permeabilized, and stained with anti-T-bet-PE and anti-IFN- $\gamma$-APC. Finally, the cells were washed with $1 \times$ Perm Wash (BD Bioscience, UK), re-suspended in FACS buffer, and collected on a FACS Calibur cytometer. Data analysis was performed using FlowJo (TreeStar Inc., Ashland, OR).

\section{Determining cytokine concentration by ELISA}

Levels of IFN- $\gamma$, TNF- $\alpha$ and IL-10 were measured using commercial enzyme linked immunosorbent assay (ELISA) kits according to the manufacturer's protocols (R\&D Systems, Minneapolis, MN). The OD values were measured in a microplate reader at $450 \mathrm{~nm}$. The concentration of cytokines in each sample was calculated using a standard curve generated from recombinant cytokines.

\section{Determining nitrite $\left(\mathrm{NO}_{2}{ }^{-}\right)$concentration}

The concentration of $\mathrm{NO}_{2}^{-}$was determined in cell supernatants using the Griess reaction (Wang et al. 2009). Briefly, $100 \mu \mathrm{L}$ of the culture supernatant from freshly isolated, unstimulated splenocytes was incubated with $100 \mu \mathrm{L}$ of Griess reagent for $10 \mathrm{~min}$ at room temperature. The $\mathrm{NO}_{2}{ }^{-}$concentration was determined by measuring the optical density at $550 \mathrm{~nm}$ (A550) in reference to the A550 of a standard $\mathrm{NaNO}_{2}$ solution.

\section{Statistical analysis}

Data are presented as the means \pm standard errors of the means (SEM). Statistically significant differences between groups were determined using the $t$ test. Time-to-event data were analyzed using the Kaplan-Meier (K-M) approach to survival analysis (SPSS 17.0). A value of $p<0.05$ was considered significant.

\section{Results}

L-Arg supplementation accelerates the death of Pb ANKAinfected C57BL/6 mice while simultaneously inhibiting parasitemia

To determine the effects of L-Arg supplementation on the outcome of ECM, C57BL/6 mice were treated with L-Arg before or after $\mathrm{Pb}$ ANKA infection. Parasitemia (Fig. 1A) and survival rate (Fig. 1B) were monitored after infection. Parasitemia was similar in the two L-Arg-treated groups, and parasitemia in both L-Arg groups was lower than the control group. On day 7 after infection, parasitemia in the mice received L-Arg pre-infection (Pre-L-Arg group) was significantly lower than that of the mice given normal saline $(p<0.01)$. However, despite reduced parasitemia, mice in the L-Arg-treated groups died at days 6-8 after infection, which was significantly earlier than the control group (days 8-11 after infection; $p<0.05$ ). Most of dying mice exhibited ruffled fur, hunching, wobbly gait, and convulsions. The clinical ECM scores were higher in the L-Arg-treated groups than the control group (Fig. 1C). Taken together, these data suggest that L-Arg-treated mice died from immune mediated pathology rather than from anemia.

\section{L-Arg enhances the pro-inflammatory immune response in $\mathrm{Pb}$ ANKA-infected C57BL/6 mice}

To elucidate the immunological mechanisms that could contribute to more rapid death of $\mathrm{Pb}$ ANKA-infected C57BL/6 mice supplemented with L-Arg, we investigated changes in the Th1 response, macrophage activation, and production of inflammatory cytokines in these mice. L-Arg treatment significantly increased the frequency and number of IFN- $\gamma$-secreting Th1 cells on day 3 after infection, compared with control group (Fig. 2A-C). Concurrently, on days 3 and 5 after infection, the levels of IFN- $\gamma$ (Fig. 2D) and TNF- $\alpha$ (Fig. 2E) were significantly increased in the L-Arg-treated groups compared with the control group. We next assessed the number and function of macrophages that related to pro-inflammatory reaction in the spleen of $\mathrm{Pb}$ ANKA-infected mice. We found that mice from the L-Arg treated groups had significantly more $\mathrm{F} 4 / 80^{+} \mathrm{CD} 36^{+}$macrophages (Fig. 3A-C) in the spleen on days 3 and 5 after infection. As it was reported that splenic macrophages produced high levels of NO in the mouse model of blood-stage malaria (Ahvazi et al. 1995), we also measured the level of
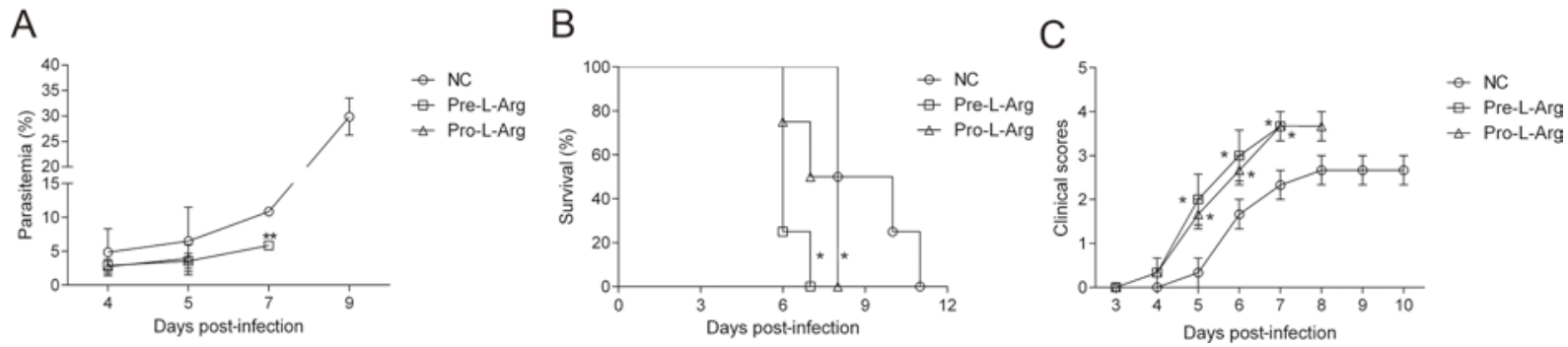

Fig. 1. L-Arg decreases the survival rate of $P b$ ANKA-infected mice.

(A) Parasitemia was determined by evaluating Giemsa-stained thin blood films under a light microscope. (B) Survival rate were monitored daily, and the data from three independent experiments were combined $(n=12)$. (C) Clinical scores for the severity of ECM were assessed daily based on the number of symptoms each mouse displayed. In A and $\mathrm{C}$, values represent the mean $\pm \mathrm{SEM}$ and results are the representative of three independent experiments each containing 3-5 mice per group. Symbols * and ** indicate $p<0.05$ and $p<0.01$, respectively, compared with the control (NC) group. 
A NC Pre-L-Arg Pro-L-Arg

d0
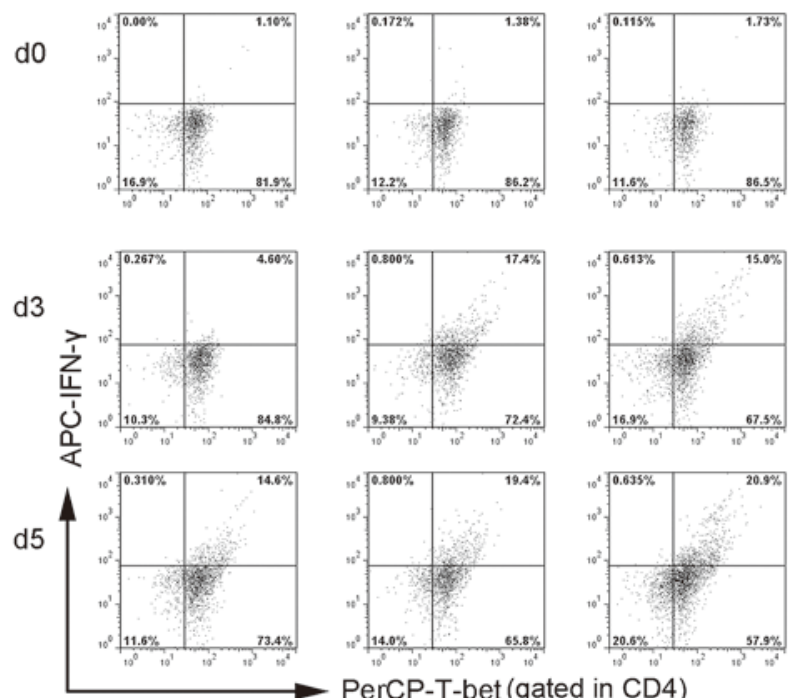

PerCP-T-bet (gated in CD4)

\section{B}

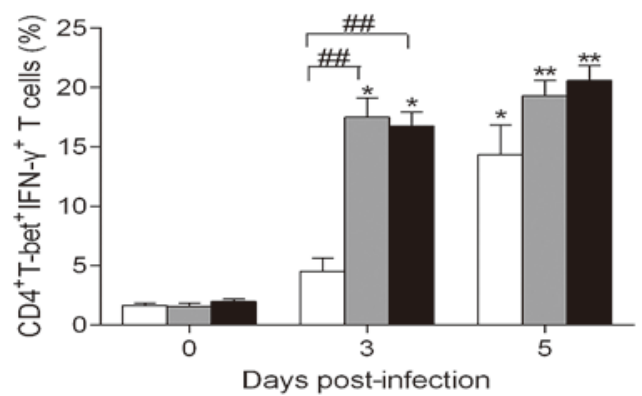

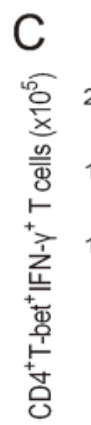
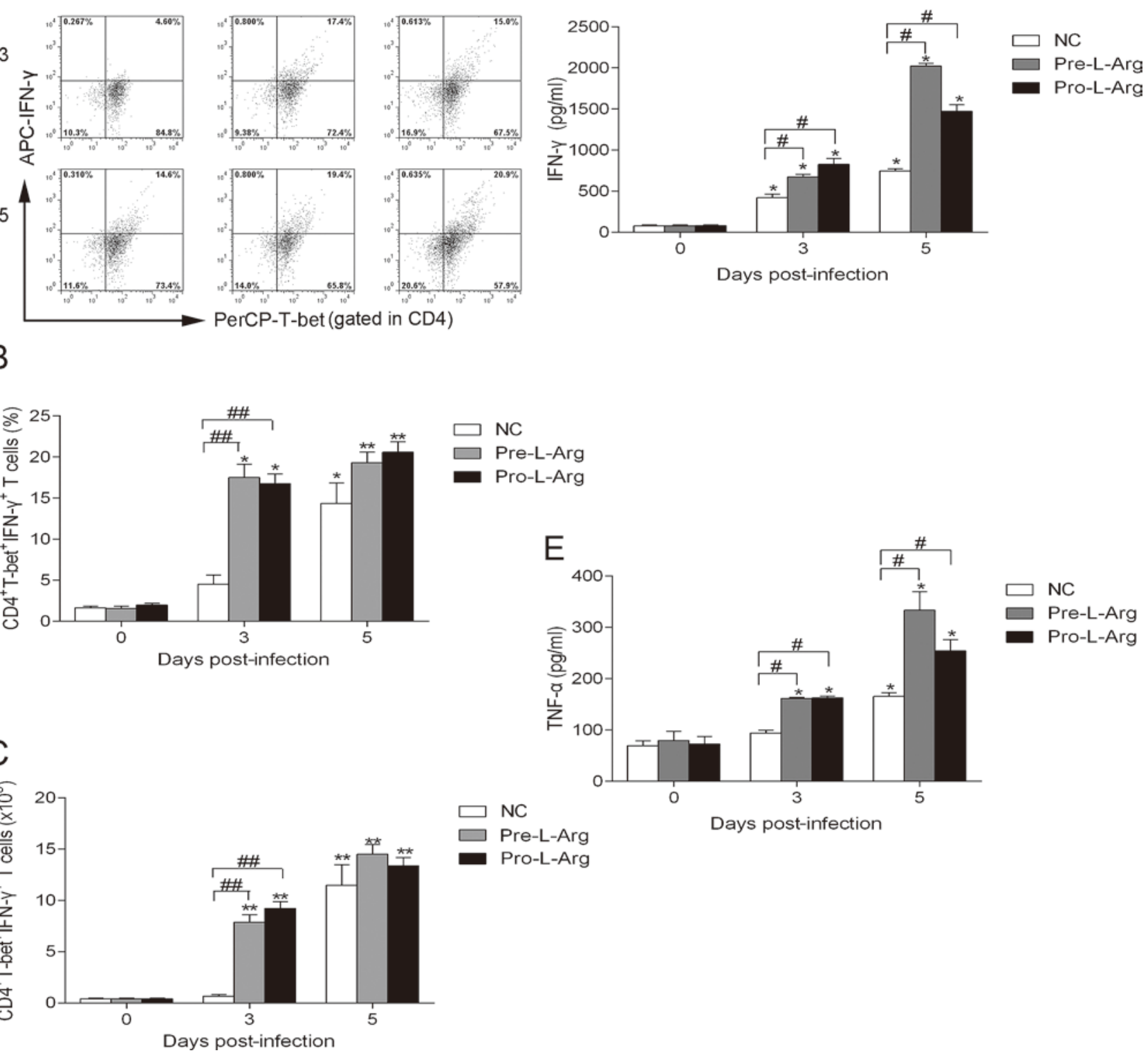

Fig. 2. L-Arg enhances Th1 immune responses in $P b$ ANKA-infected mice.

$\mathrm{CD} 4^{+}$T-bet ${ }^{+} \mathrm{IFN}-\gamma^{+} \mathrm{Th} 1$ cells (gated on $\mathrm{CD}^{+}$) were analyzed by flow cytometry and displayed in dot plot (A). Their percentage and absolute number are shown in B and C. Concentrations of cytokine IFN- $\gamma$ (D) and TNF- $\alpha$ (E) in the culture supernatant of spleen cells were determined by ELISA. Values represent the mean $\pm \operatorname{SEM}(n=3$ mice per group). Results are representative of three independent experiments. Symbols * and $* *$ indicate statistically significant differences ( $p<0.05$ and $p<0.01$, respectively) between infected groups and uninfected groups; \# and \#\# indicate statistically significant differences ( $p<0.05$ and $p<0.01$, respectively) between L-Arg-treated mice and normal saline-treated mice.

NO in the culture supernatant of splenocytes. As expected, splenocytes from mice in the L-Arg groups showed much higher NO production than that from the control group on days 3 and 5 after infection (Fig. 3D). Thus, there was an increased pro-inflammatory response in L-Arg-supplemented C57BL/6 mice infected with $P b$ ANKA, which might contribute to the development of $\mathrm{CM}$. 
A
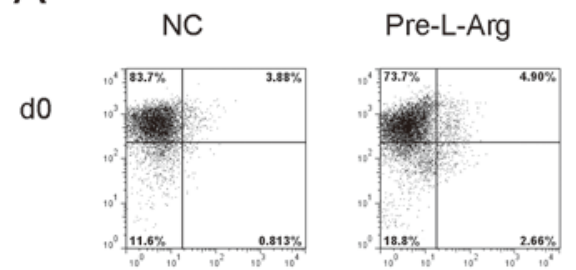

Pro-L-Arg
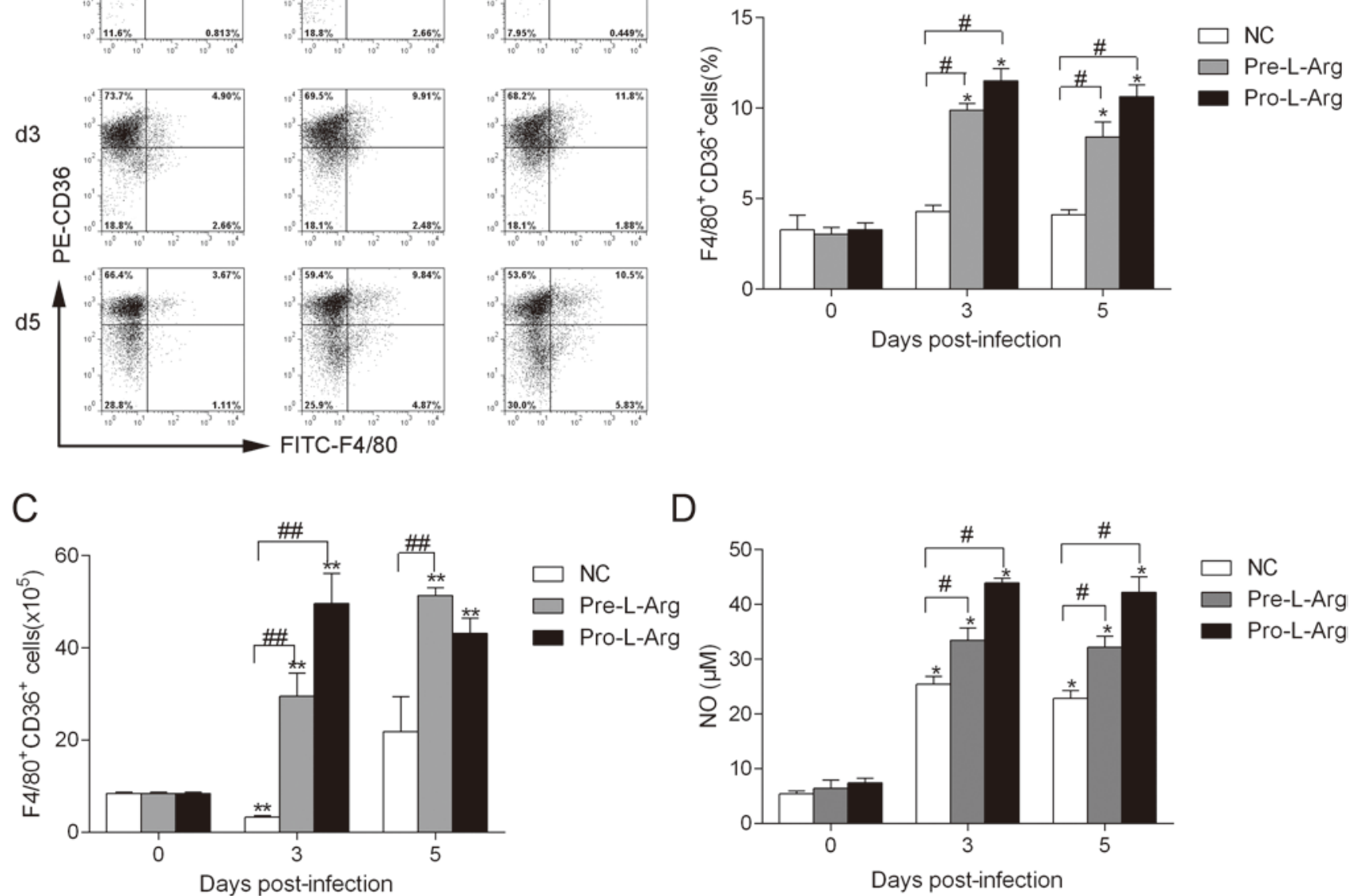

Fig. 3. L-Arg promotes the expansion and activation of macrophages in $\mathrm{Pb}$ ANKA-infected mice.

The population of $\mathrm{F} 4 / 80^{+} \mathrm{CD} 36^{+}$cell in splenocytes was analyzed by flow cytometry and displayed in dot plot (A). Their percentage and absolute number are shown in $\mathrm{B}$ and $\mathrm{C}$. The level of $\mathrm{NO}_{2}^{-}$in the supernatants of cultured splenocytes was determined by Griess reaction (D). Values represent the mean \pm SEM ( $n=3$ mice per group). Results are representative of three independent experiments. Symbols * and ** indicate statistically significant differences $(p<$ 0.05 and $p<0.01$, respectively) between infected groups and uninfected groups; \# and \#\# indicate statistically significant differences ( $p<0.05$ and $p<0.01$, respectively) between L-Arg-treated mice and normal saline-treated mice.

L-Arg stimulates $D C$ activation and proliferation in $\mathrm{Pb}$ ANKA-infected C57BL/6 mice

DCs play a critical role in the activation and polarization of naive Th cells. To determine the immunomodulatory effects of L-Arg on DCs, we examined the frequency and maturation of DCs from $\mathrm{Pb}$ ANKA-infected mice. The percentage and numbers of myeloid DCs (Fig. 4A-C) and plasmacytoid DCs (Fig. 4D-F) in L-Arg-treated groups were significantly higher than that in the control groups on days 3 and 5 after infection ( $p<0.05$ and $p<0.01$, respectively). We next assessed the expression of MHCII and CD86 on splenic CD11 ${ }^{+}$DCs, which are essential for inducing a T-cell response. As expected, L-Arg significantly enhanced the percentages and numbers of $\mathrm{CD} 11 \mathrm{c}^{+} \mathrm{MHCII}^{+} \mathrm{DCs}$ (Fig. 5A-C) and $\mathrm{CD} 11 \mathrm{c}^{+} \mathrm{CD} 86^{+} \mathrm{DCs}$ (Fig. 5D-F) at day 3 after infection $(p<0.05)$ and day 5 after infection $(p<0.05)$. As the pattern recognition molecules toll-like receptors (TLRs) have been known to be involved in the recognition of protozoan parasites (Iwasaki and Medzhitov 2004), we quantified the expression of TLR9 on DCs. As expected, the percentages and number of

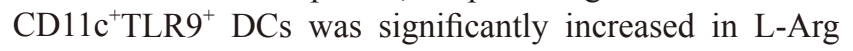
treated groups compared with control group (Fig. 5G-I).

L-Arg has no effect on the number of Tregs or the level of IL-10 in Pb ANKA-infected C57BL/6 mice

$\mathrm{CD}^{+} \mathrm{CD} 25^{+} \mathrm{Foxp}^{+}$Tregs have an important role in regulating pro-inflammatory responses in rodent malaria models during early infection. The potential regulatory mechanisms are associated with the induction of IL-10 (Chen et al. 2009). To further investigate the effects of L-Arg supplementation on Tregs and IL-10 production, we 
A
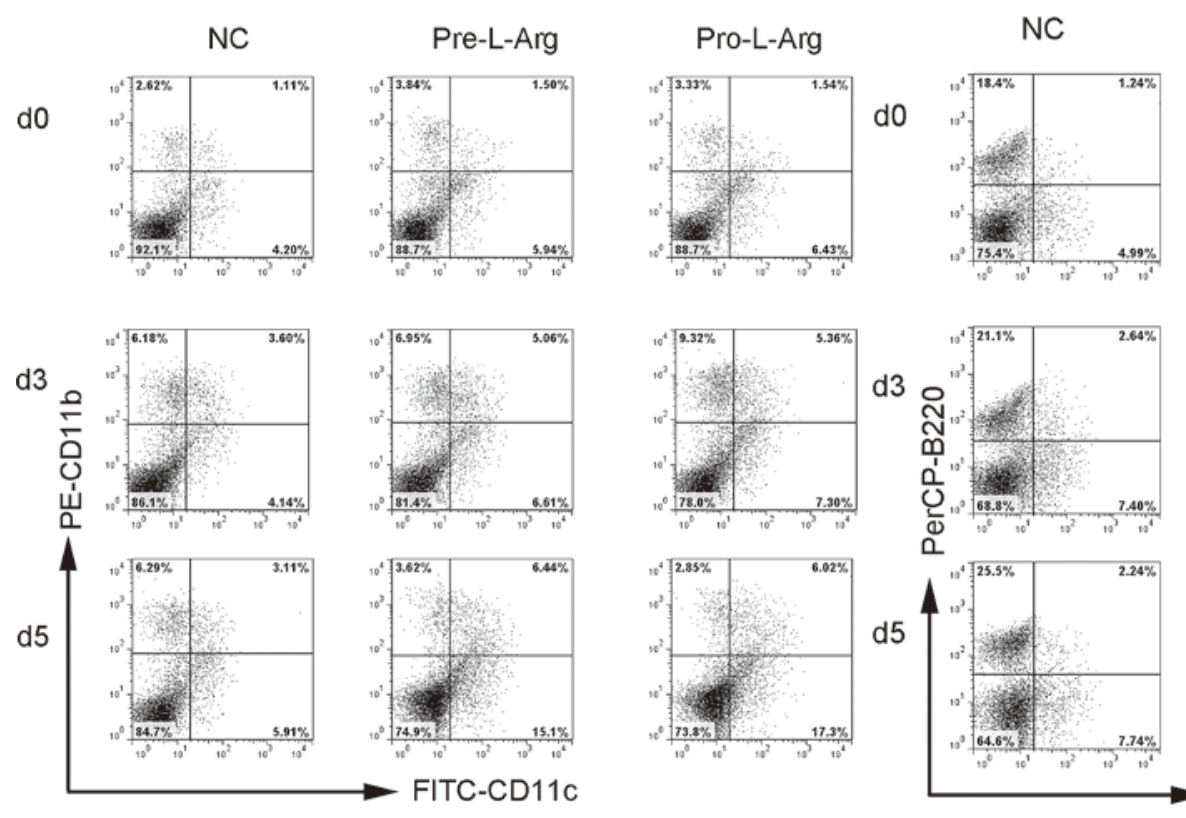

Pre-L-Arg

Pro-L-Arg
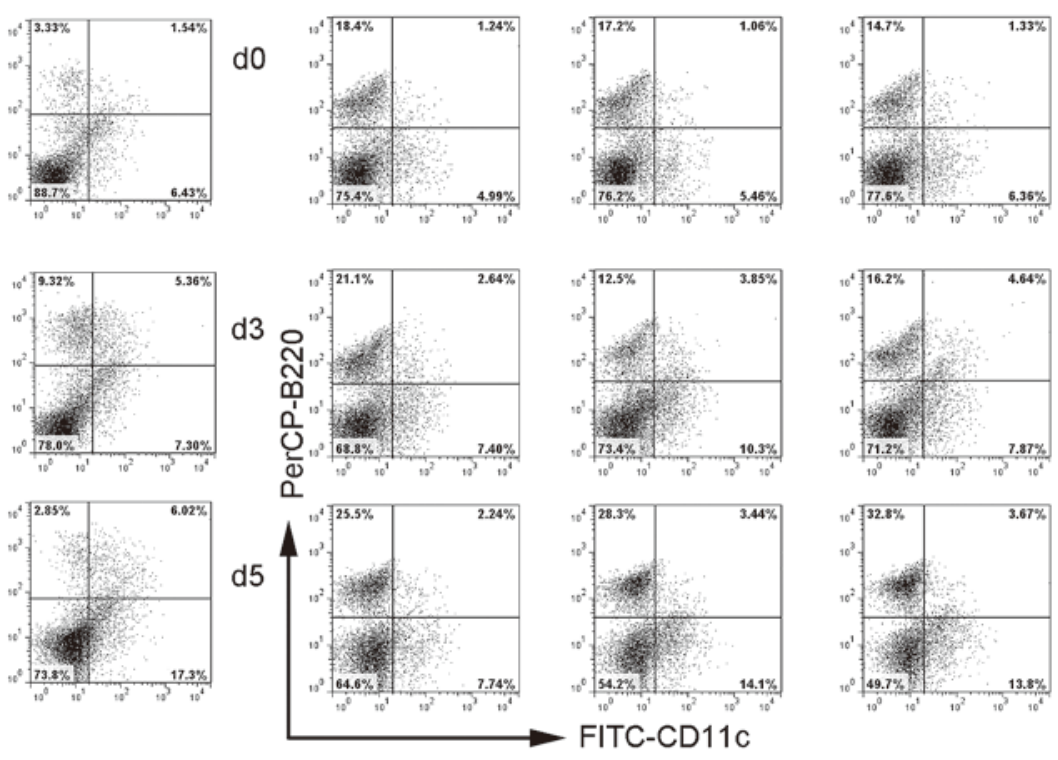

B

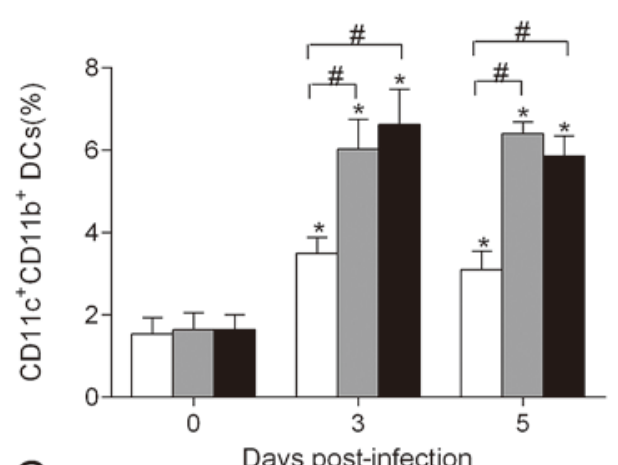

C

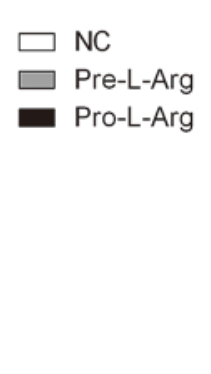

\section{$\mathrm{E}$}
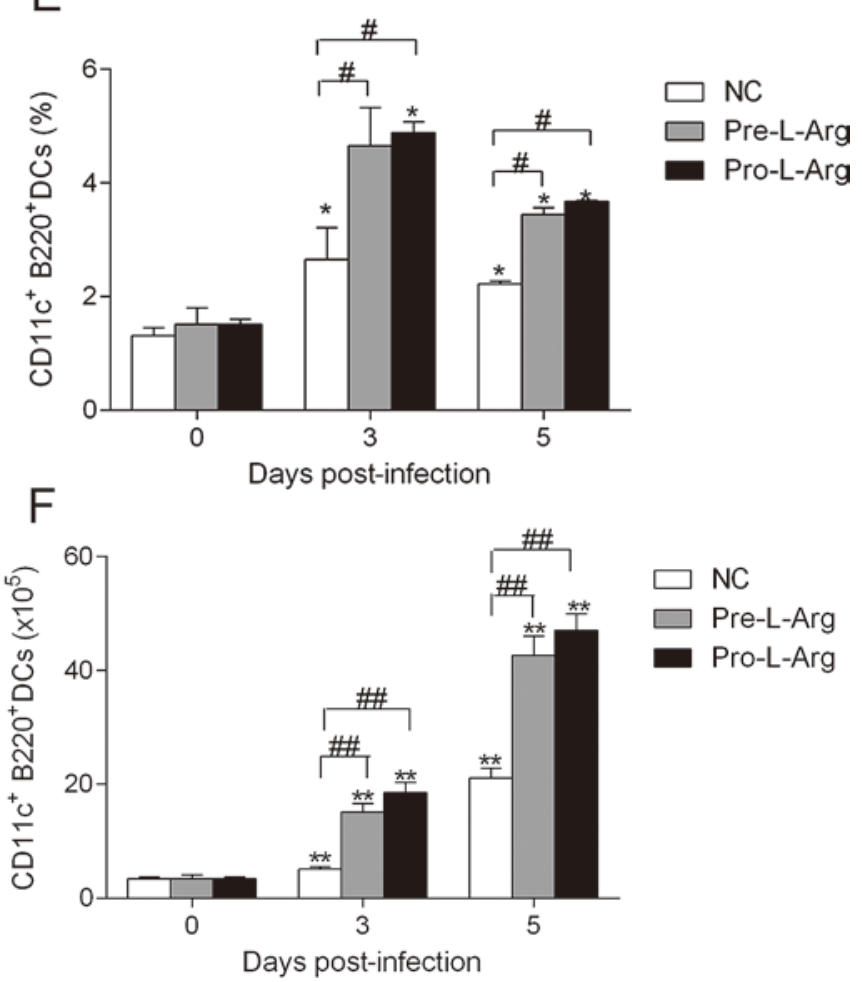

Fig. 4. L-Arg promotes the proliferation of DCs' subsets in $\mathrm{Pb}$ ANKA-infected mice.

The percentage of CD11 $\mathrm{c}^{+} \mathrm{CD} 11 \mathrm{~b}^{+}$DCs (A and B) and CD11 $\mathrm{c}^{+} \mathrm{B} 220+\mathrm{DCs}(\mathrm{D}$ and E) in the spleen cells was evaluated by flow cytometry and shown in dot plot and bar graph. The absolute number of these cells was calculated and shown ( $\mathrm{C}$ and F). Data are presented as the mean $\pm \operatorname{SEM}(n=3$ mice per group). Results are representative of three independent experiments. Symbols $*$ and $* *$ indicate statistically significant differences $(p<0.05$ and $p<0.01$, respectively) between infected groups and uninfected groups; \# and \#\# indicate statistically significant differences $(p<0.05$ and $p<$ 0.01 , respectively) between L-Arg-treated mice and normal saline-treated mice. 
A
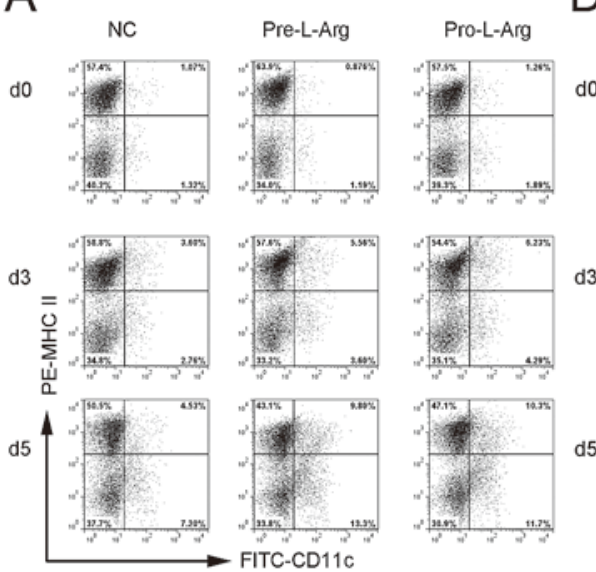

B

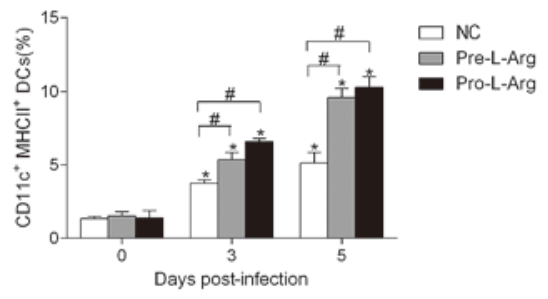

C

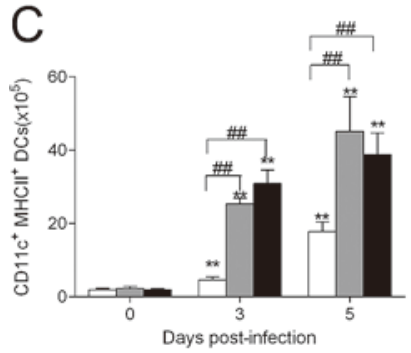

$\mathrm{D}$

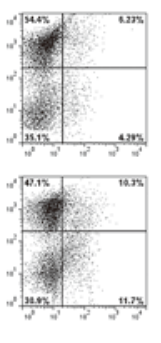

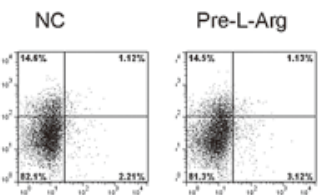
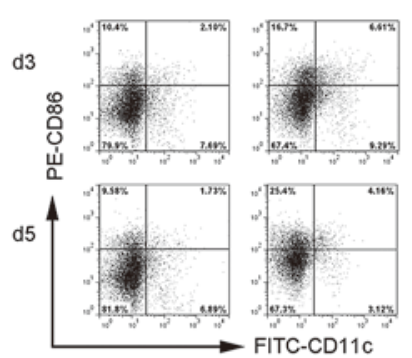

G
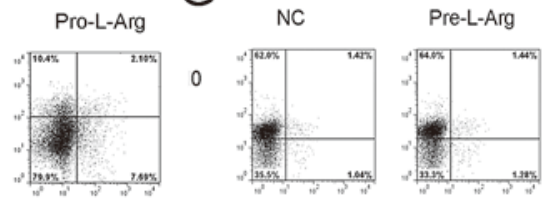

Pro-L-Arg
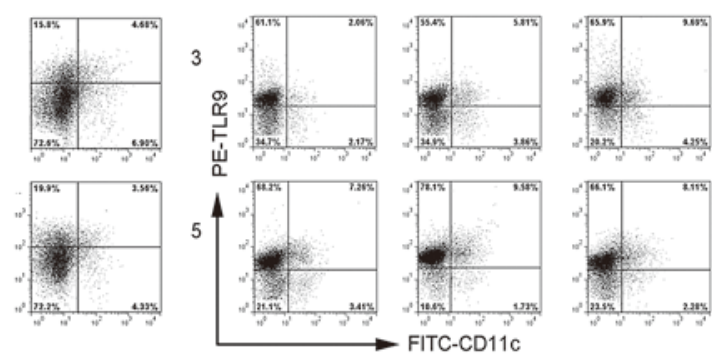

$\mathrm{H}$
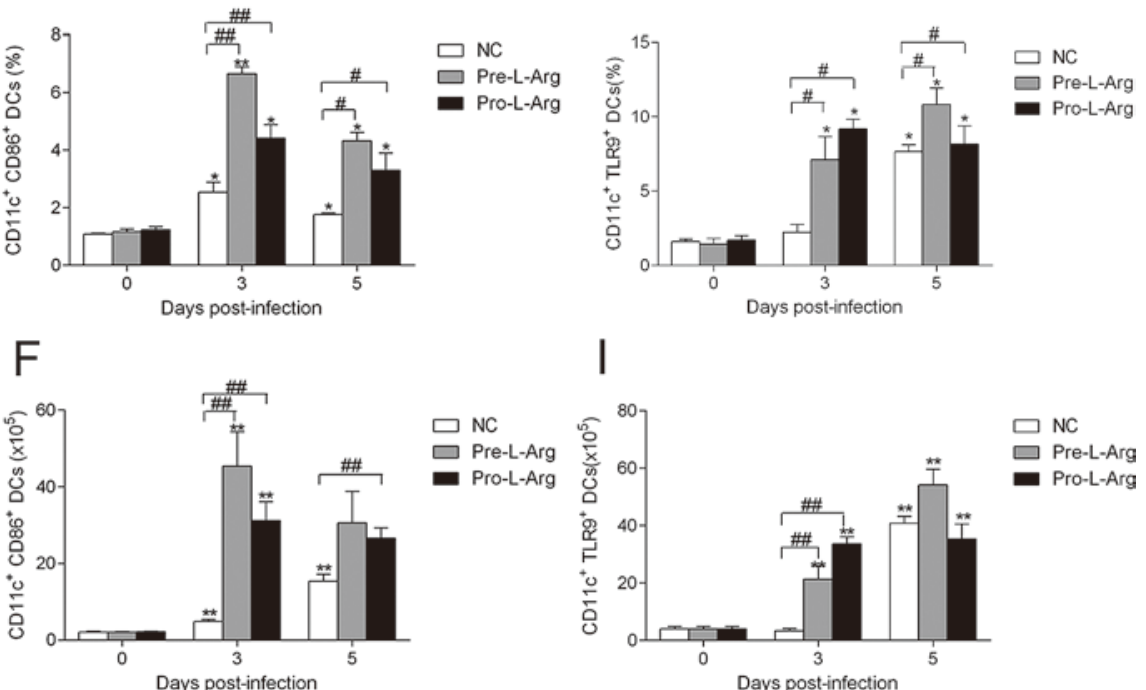

I

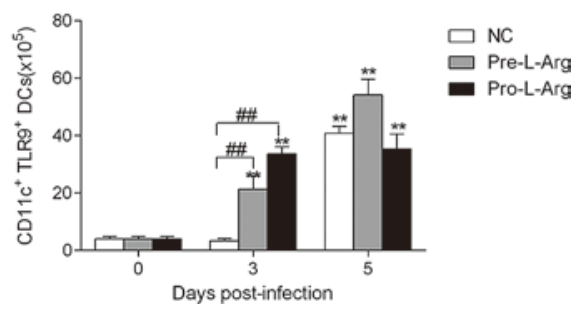

Fig. 5. L-Arg promotes the expression of DCs' phenotype in $P b$ ANKA-infected mice.

The expression of MHCII (A), CD86 (D) and TLR9 (G) on splenic CD11 $\mathrm{c}^{+}$DCs was evaluated by flow cytometry and displayed in dot plot. The percentage and absolute number of $\mathrm{CD} 11 \mathrm{c}^{+} \mathrm{MHCII}^{+}(\mathrm{B}$ and $\mathrm{C}) \mathrm{CD} 11 \mathrm{c}^{+} \mathrm{CD} 86$ (E and F) and CD11 $\mathrm{c}^{+} \mathrm{TLR}^{+} \mathrm{DCs}(\mathrm{H}$ and $\mathrm{I})$ was shown in bar graph. Data is presented as the mean $\pm \operatorname{SEM}(n=3$ mice per group). Results are representative of three independent experiments. Symbols $*$ and $* *$ indicate statistically significant differences ( $p<0.05$ and $p<0.01$, respectively) between infected groups and uninfected groups; \# and \#\# indicate statistically significant differences ( $p<0.05$ and $p<0.01$, respectively) between L-Arg-treated mice and normal saline-treated mice.

determined the percentage and number of Tregs as well as levels of IL-10 produced by splenocytes in $\mathrm{Pb}$ ANKAinfected C57BL/6 mice. As shown in Fig. 6, the percentage and number of Tregs increased in the control, Pre-L-Arg, and Pro-L-Arg groups after parasite infection. However, there was no significant difference between the L-Arg treated groups and the control group (Fig. 6A-C). Similar results were observed regarding the production of splenic IL-10 (Fig. 6D). These data suggested that the increased Th1 response in the ECM model supplemented with L-Arg was not due to deficient Tregs or IL-10.

\section{Discussion}

In this study, we demonstrate for the first time that oral L-Arg treatment, regardless of whether it is pre- or post- infection, significantly decreases the survival time of mice with ECM probably by enhancing Th1 immune responses. Our findings provide important insights into the usage of L-Arg in areas where malaria is endemic.

L-Arg is a conditionally essential amino acid for adults and plays a critical role in regulating the immune response (Tapiero et al. 2002; Bronte and Zanovello 2005). L-Arg is important primarily because of its role as a precursor for NO synthesis. NO is a free radical molecule that is synthesized by NO synthase (NOS) in all mammalian cells, but excessive NO production can be pathogenic in both acute and chronic models of inflammation (Salvemini and Marino 1998). In case of adults who do not develop CM, have a premunitive status, or were previously infected with $P$. falciparum, L-Arg is a potential adjunctive therapy for clinical 

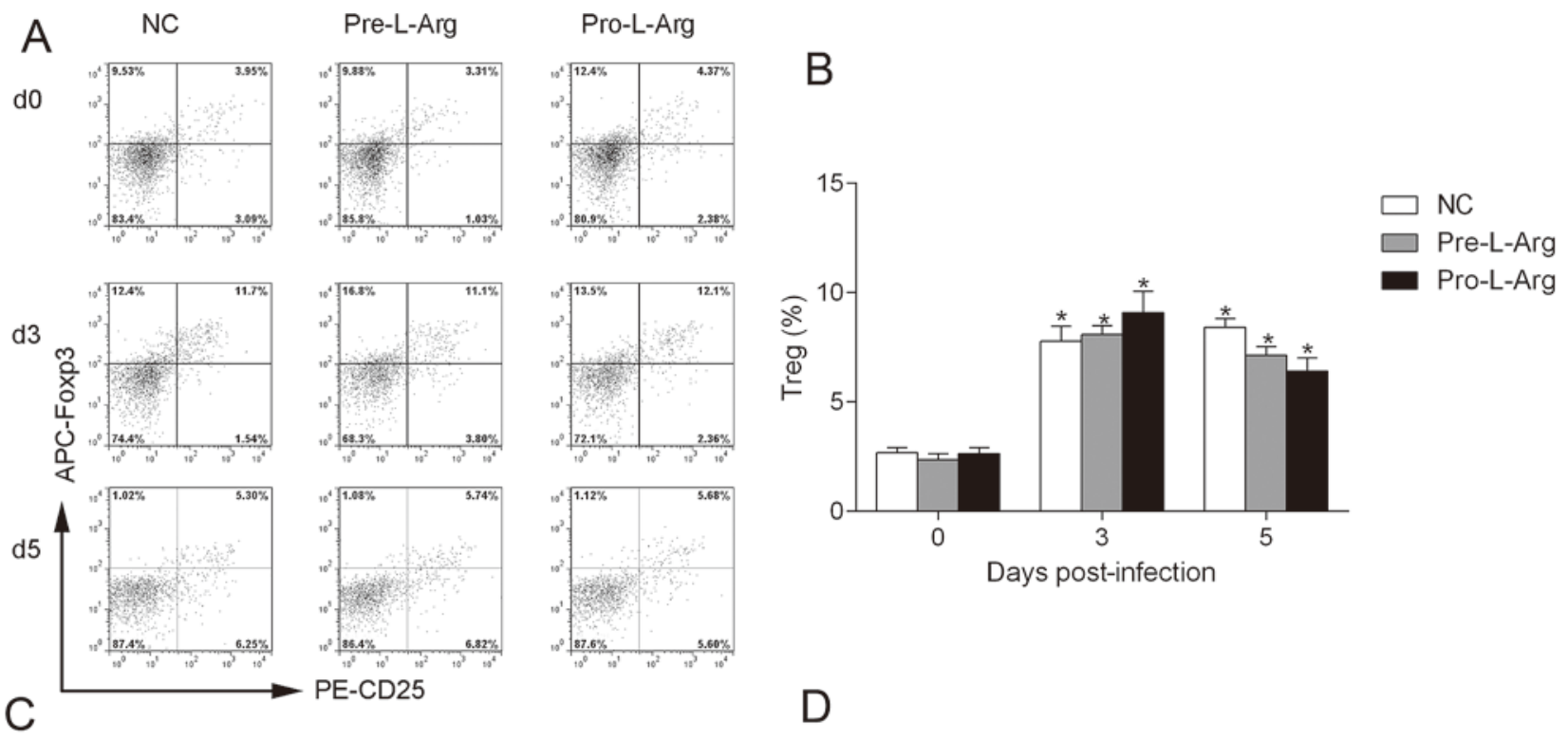

Days post-infection

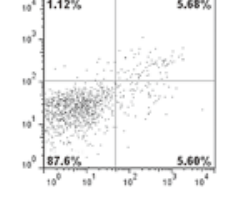

D
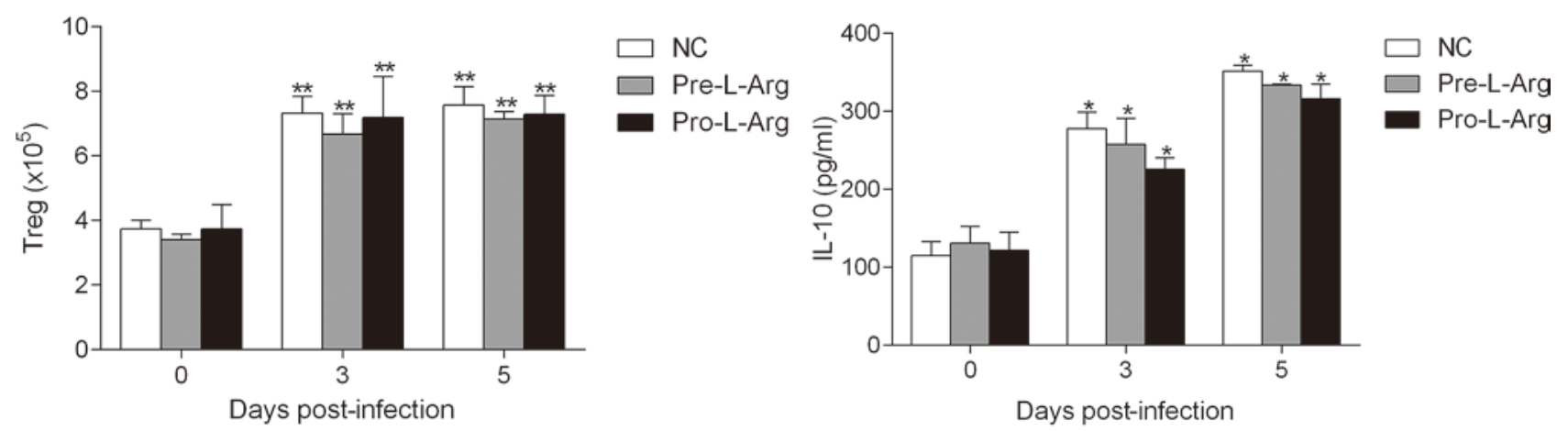

Fig. 6. L-Arg has no effect on Tregs in $P b$ ANKA-infected mice.

The percentage of Tregs (gated on $\mathrm{CD}^{+}$) in the spleen was evaluated by flow cytometry and shown in dot plot (A) and bar graph (B) at 0,3 , and 5 days after infection. The absolute number of these cells is shown (C). The level of IL-10 in the culture supernatant of splenocytes was measured with ELISA (D). Data are presented as the mean \pm SEM $(n=3$ mice per group). Results are representative of three independent experiments. Symbols * and ** indicate statistically significant differences ( $p<0.05$ and $p<0.01$, respectively) between infected groups and uninfected groups.

recovery from severe malaria (Yeo et al. 2007). We previously showed that L-Arg potentiated Th1 immune response during Plasmodium yoelii (Py) 17XL infection, which supported that L-Arg was an effective immunomodulator for uncomplicated mouse malaria (Zhu et al. 2012). However, enhanced pro-inflammatory immune response could result in immunopathology in malaria patients, especially in children under five, who develop CM more frequently than adults during $P$. falciparum infection. Therefore, we wanted to address whether L-Arg supplementation was an appropriate adjunct therapy for young children in malaria endemic area. In the current study, we observed that L-Arg treatment accelerated the death of mice with ECM. We also found that L-Arg increased Th1 response to $P b$ ANKA infection as it was previously shown in Py17XL-infected mice. Whereas the elevated Th1 response contributed to the survival of mice during Py17XL infection, it was associated with aggravation of $\mathrm{CM}$ in mice infected with $\mathrm{Pb}$ ANKA. Our findings suggested that, although L-Arg sup- plementation is safe in adult malaria patients, it might be detrimental for young children who are at more risk for $\mathrm{CM}$ during $P$. falciparum infection.

Clinically CM is characterized by convulsions, seizures, and coma. Many studies have shown that parasitemia and the subsequent potent pro-inflammatory response are essential for developing CM (Walther et al. 2009). In a commonly used murine CM model, the $\mathrm{Pb}$ ANKA-infected C57BL/6 mice, the development of CM is associated with high levels of inflammatory mediators such as IFN- $\gamma$, TNF$\alpha$, and NO during infection (Hunt and Grau 2003; Engwerda et al. 2005; Jain et al. 2008; Edgerton et al. 2009; Wang et al. 2009). In agreement with these work, here we found that splenocytes producing pro-inflammatory mediators, such as IFN- $\gamma$-secreting Th 1 cells and $\mathrm{F} 4 / 80^{+} \mathrm{CD} 36^{+}$cells, were both increased in spleen from $\mathrm{Pb}$ ANKA-infected mice treated with L-Arg. In addition, the levels of IFN- $\gamma$, TNF- $\alpha$, and NO were also significantly raised by L-Arg treatment during infection. It needs to be mentioned that 
Th1 immune response was not enhanced in Pre-L-Arg group on day 0 post infection. This implies that prophylactic supplementation of L-Arg for one week had no direct effects on the function of resting $\mathrm{T}$ cells. The enhancement of Th1 response by L-Arg may largely be secondary to the modification of DCs' function. Despite that, our data indicated that L-Arg potentiated Th1 response and the production of pro-inflammatory cytokines in $\mathrm{Pb}$ ANKA-infected C57BL/6 mice, which may contribute to the aggravation of CM.

We also noticed that L-Arg treatment reduced the level of parasitemia while increasing Th1 response in the $\mathrm{Pb}$ ANKA-infected C57BL/6 mice. This result is reasonable since Th1 response plays a central role in controlling parasitemia. However, there is the possibility that L-Arg acts directly on the viability of malaria parasite. It was reported that $P$. falciparum parasites under the pressure of S-nitroso$\mathrm{N}$-acetyl-penicillamine (SNAP), the NO donor, died by autophagic-like cell death (Totino et al. 2008). Another study showed that NO production increased in $P$. falciparum parasites incubated with L-Arg in vitro (Rey et al. 2014). These results suggest that L-Arg supplementation may have a direct effect on the viability of malaria parasites in vivo, and more work needs to be done to prove it.

DCs are heterogeneous antigen presenting cells that have a key role in initiating and regulating cell-mediated immune responses (Banchereau et al. 2000). DCs are required to initiate the malaria parasite-specific $\mathrm{CD}^{+} \mathrm{T}$ cell response, and subsequently CM (deWalick et al. 2007). In this study, we showed that L-Arg treatment increased the number of DCs and promoted their maturation in spleen of $\mathrm{Pb}$ ANKA-infected mice. These changes could have contributed to enhancing the Th1 response in mice treated with L-Arg in our experiment. However, how L-Arg treatment influence DCs' number and function is not clear. It is known that DCs' function is regulated by multiple tissue factors, such as IFN- $\gamma$ and CD40 ligand produced by activated gamma delta $\mathrm{T}$ cells during Plasmodium infection (Yanez et al. 1999; Inoue et al. 2012). Thus, L-Arg treatment may affect DCs' number and function via both direct and indirect ways. Studies to understand how supplementing L-Arg might affect DC function would be worth pursuing in the future studies.

TLRs are critical components of the innate immune system and recognize conserved microbial products including lipids, proteins, and nucleic acids (Akira et al. 2006). A role for TLRs in the pathogenesis of malaria has been proposed by several different studies. Although the data is conflicting, there is a growing body of literature that supports viewing TLRs as central regulators of pro-inflammatory responses in both rodent and human malaria (Ishii et al. 2005; Zhu et al. 2005; Coban et al. 2007; Parroche et al. 2007). TLR9 is thought to play an essential role in CM pathogenesis by helping recruit immune cells into the brain, or in the case of severe malaria, for its role in inducing Tregs and/or synergy with IFN- $\gamma$ signaling (Coban et al.
2007; Hisaeda et al. 2008). DCs from TLR9 (-/-) and MyD88 (-/-) mice produced significantly lower levels of pro-inflammatory cytokines, but higher levels of antiinflammatory cytokines, than wild-type mice (Gowda et al. 2012). Consistent with previous reports, TLR9 expression on DCs from L-Arg treated mice was significantly increased in this study, and was associated with elevated pro-inflammatory cytokine levels. However, the mechanism underlying L-Arg regulation of TLR9 expression remains unclear.

Tregs are a T-cell subset that has different immunoregulatory effects from Th1 and Th2 cells. Tregs inhibit the Th1 response by modifying DC function, producing IL-10, and inducing $\mathrm{CD}^{+} \mathrm{T}$ cell apoptosis (Slade and Langhorne 1989; Zheng et al. 2009), which facilitates immune evasion by the parasite (Hisaeda et al. 2004). Previous studies have shown that Tregs contributed to determining the incidence and outcome of $\mathrm{CM}$ in $\mathrm{Pb}$ ANKA-infected mice by altering the balance of pro- (IFN- $\gamma$, TNF- $\alpha$, IL-6, IL-17, and NO) and anti-inflammatory (IL-10) responses (Lopansri et al. 2003; Amante et al. 2007; Yeo et al. 2008b). Therefore, we assessed the effect of L-Arg on the percentage of Tregs and the production of the anti-inflammatory cytokine IL-10. In the $P b$ ANKA/C57BL/6 model, L-Arg affected neither the percentage of Tregs nor IL-10 production. This suggested that Tregs were not likely contributed to the enhanced Th1 response in the L-Arg supplemented CM model.

As NO is a potential target for therapy of severe malaria, a variety of strategies has been developed to improve NO bioavailability. Difference in NO donors, dosage and administration route resulted in controversial studies (Martins et al. 2012). In our experiments, oral L-Arg treatment accelerates the death of mice in the $\mathrm{Pb}$ ANKA/ C57BL/6 ECM model. This effect is associated with enhanced Th1 responses and activation of DCs, but did not involve Tregs. We wish to emphasize that in this study L-Arg treatment enhanced the Th1 immune response. Although L-Arg has a protective role in non-CM patients, it may contribute to a lethal outcome in $\mathrm{CM}$ patients. Therefore, L-Arg should be used with caution in malaria patients of different ages in the endemic areas. Although supplementing with L-Arg has generally been safe, our study provides additional information about potentially lifethreatening applications of L-Arg in CM patients in malaria-endemic areas.

\section{Acknowledgments}

We thank Dr. Motomi Torii (Ehime University Graduate School of Medicine, Ehime, Japan) for his guidance in this research and providing the malaria parasite strains. This study was funded by Grant 81101278 from the National Natural Science Foundation of China and Grant-in-Aid (LJQ2011084) from the Liaoning Provincial Development Program for outstanding young scholars, China. We are grateful to all other staff in the College of Animal Science and Technology.

\section{Conflict of Interest}

The authors declare no conflict of interest. 


\section{References}

Ahvazi, B.C., Jacobs, P. \& Stevenson, M.M. (1995) Role of macrophage-derived nitric oxide in suppression of lymphocyte proliferation during blood-stage malaria. J. Leukoc. Biol., 58, 23-31.

Akira, S., Uematsu, S. \& Takeuchi, O. (2006) Pathogen recognition and innate immunity. Cell, 124, 783-801.

Amante, F.H., Stanley, A.C., Randall, L.M., Zhou, Y., Haque, A., McSweeney, K., Waters, A.P., Janse, C.J., Good, M.F., Hill, G.R. \& Engwerda, C.R. (2007) A role for natural regulatory T cells in the pathogenesis of experimental cerebral malaria. Am. J. Pathol., 171, 548-559.

Anstey, N.M., Weinberg, J.B., Hassanali, M.Y., Mwaikambo, E.D., Manyenga, D., Misukonis, M.A., Arnelle, D.R., Hollis, D., McDonald, M.I. \& Granger, D.L. (1996) Nitric oxide in Tanzanian children with malaria: inverse relationship between malaria severity and nitric oxide production/nitric oxide synthase type 2 expression. J. Exp. Med., 184, 557-567.

Banchereau, J., Briere, F., Caux, C., Davoust, J., Lebecque, S., Liu, Y.J., Pulendran, B. \& Palucka, K. (2000) Immunobiology of dendritic cells. Annu. Rev. Immunol., 18, 767-811.

Belnoue, E., Kayibanda, M., Vigario, A.M., Deschemin, J.C., van Rooijen, N., Viguier, M., Snounou, G. \& Renia, L. (2002) On the pathogenic role of brain-sequestered alphabeta CD8+ T cells in experimental cerebral malaria. J. Immunol., 169, 6369-6375.

Bronte, V. \& Zanovello, P. (2005) Regulation of immune responses by L-arginine metabolism. Nat. Rev. Immunol., 5, 641-654.

Chen, G., Liu, J., Wang, Q.H., Wu, Y., Feng, H., Zheng, W., Guo, S.Y., Li, D.M., Wang, J.C. \& Cao, Y.M. (2009) Effects of CD4(+)CD25(+)Foxp3(+)regulatory T cells on early Plasmodium yoelii 17XL infection in BALB/c mice. Parasitology, 136, 1107-1120.

Coban, C., Ishii, K.J., Horii, T. \& Akira, S. (2007) Manipulation of host innate immune responses by the malaria parasite. Trends Microbiol., 15, 271-278.

de Jonge, W.J., Kwikkers, K.L., te Velde, A.A., van Deventer, S.J., Nolte, M.A., Mebius, R.E., Ruijter, J.M., Lamers, M.C. \& Lamers, W.H. (2002) Arginine deficiency affects early B cell maturation and lymphoid organ development in transgenic mice. J. Clin. Invest., 110, 1539-1548.

de Souza, J.B. \& Riley, E.M. (2002) Cerebral malaria: the contribution of studies in animal models to our understanding of immunopathogenesis. Microbes Infect., 4, 291-300.

deWalick, S., Amante, F.H., McSweeney, K.A., Randall, L.M., Stanley, A.C., Haque, A., Kuns, R.D., MacDonald, K.P., Hill, G.R. \& Engwerda, C.R. (2007) Cutting edge: conventional dendritic cells are the critical APC required for the induction of experimental cerebral malaria. J. Immunol., 178, 60336037.

Edgerton, C., Crispin, J.C., Moratz, C.M., Bettelli, E., Oukka, M., Simovic, M., Zacharia, A., Egan, R., Chen, J., Dalle Lucca, J.J., Juang, Y.T. \& Tsokos, G.C. (2009) IL-17 producing CD4+ $\mathrm{T}$ cells mediate accelerated ischemia/reperfusioninduced injury in autoimmunity-prone mice. Clin. Immunol., 130, 313-321.

Engwerda, C., Belnoue, E., Gruner, A.C. \& Renia, L. (2005) Experimental models of cerebral malaria. Curr. Top. Microbiol. Immunol., 297, 103-143.

Franke-Fayard, B., Janse, C.J., Cunha-Rodrigues, M., Ramesar, J., Buscher, P., Que, I., Lowik, C., Voshol, P.J., den Boer, M.A., van Duinen, S.G., Febbraio, M., Mota, M.M. \& Waters, A.P. (2005) Murine malaria parasite sequestration: CD36 is the major receptor, but cerebral pathology is unlinked to sequestration. Proc. Natl. Acad. Sci. USA, 102, 11468-11473.

Gowda, N.M., Wu, X. \& Gowda, D.C. (2012) TLR9 and MyD88 are crucial for the development of protective immunity to malaria. J. Immunol., 188, 5073-5085.

Gupta, S., Snow, R.W., Donnelly, C.A., Marsh, K. \& Newbold, C. (1999) Immunity to non-cerebral severe malaria is acquired after one or two infections. Nat. Med., 5, 340-343.

Hansen, D.S. (2012) Inflammatory responses associated with the induction of cerebral malaria: lessons from experimental murine models. PLoS Pathog., 8, e1003045.

Hearn, J., Rayment, N., Landon, D.N., Katz, D.R. \& de Souza, J.B. (2000) Immunopathology of cerebral malaria: morphological evidence of parasite sequestration in murine brain microvasculature. Infect. Immun., 68, 5364-5376.

Hisaeda, H., Maekawa, Y., Iwakawa, D., Okada, H., Himeno, K., Kishihara, K., Tsukumo, S. \& Yasutomo, K. (2004) Escape of malaria parasites from host immunity requires CD4+ CD25+ regulatory T cells. Nat. Med., 10, 29-30.

Hisaeda, H., Tetsutani, K., Imai, T., Moriya, C., Tu, L., Hamano, S., Duan, X., Chou, B., Ishida, H., Aramaki, A., Shen, J., Ishii, K.J., Coban, C., Akira, S., Takeda, K., Yasutomo, K., Torii, M. \& Himeno, K. (2008) Malaria parasites require TLR9 signaling for immune evasion by activating regulatory $\mathrm{T}$ cells. J. Immunol., 180, 2496-2503.

Hunt, N.H. \& Grau, G.E. (2003) Cytokines: accelerators and brakes in the pathogenesis of cerebral malaria. Trends Immunol., 24, 491-499.

Inoue, S., Niikura, M., Takeo, S., Mineo, S., Kawakami, Y., Uchida, A., Kamiya, S. \& Kobayashi, F. (2012) Enhancement of dendritic cell activation via CD40 ligand-expressing gammadelta $\mathrm{T}$ cells is responsible for protective immunity to Plasmodium parasites. Proc. Natl. Acad. Sci. USA, 109, 12129-12134.

Ishii, K.J., Coban, C. \& Akira, S. (2005) Manifold mechanisms of Toll-like receptor-ligand recognition. J. Clin. Immunol., 25, 511-521.

Iwasaki, A. \& Medzhitov, R. (2004) Toll-like receptor control of the adaptive immune responses. Nat. Immunol., 5, 987-995.

Jain, V., Armah, H.B., Tongren, J.E., Ned, R.M., Wilson, N.O., Crawford, S., Joel, P.K., Singh, M.P., Nagpal, A.C., Dash, A.P., Udhayakumar, V., Singh, N. \& Stiles, J.K. (2008) Plasma IP-10, apoptotic and angiogenic factors associated with fatal cerebral malaria in India. Malar. J., 7, 83.

Kropf, P., Baud, D., Marshall, S.E., Munder, M., Mosley, A., Fuentes, J.M., Bangham, C.R., Taylor, G.P., Herath, S., Choi, B.S., Soler, G., Teoh, T., Modolell, M. \& Muller, I. (2007) Arginase activity mediates reversible $\mathrm{T}$ cell hyporesponsiveness in human pregnancy. Eur. J. Immunol., 37, 935-945.

Lopansri, B.K., Anstey, N.M., Weinberg, J.B., Stoddard, G.J., Hobbs, M.R., Levesque, M.C., Mwaikambo, E.D. \& Granger, D.L. (2003) Low plasma arginine concentrations in children with cerebral malaria and decreased nitric oxide production. Lancet, 361, 676-678.

Martins, Y.C., Zanini, G.M., Frangos, J.A. \& Carvalho, L.J. (2012) Efficacy of different nitric oxide-based strategies in preventing experimental cerebral malaria by Plasmodium berghei ANKA. PLoS One, 7, e32048.

Miller, L.H., Baruch, D.I., Marsh, K. \& Doumbo, O.K. (2002) The pathogenic basis of malaria. Nature, 415, 673-679.

Nie, C.Q., Bernard, N.J., Schofield, L. \& Hansen, D.S. (2007) CD4+ CD25+ regulatory T cells suppress CD4+ T-cell function and inhibit the development of Plasmodium bergheispecific TH1 responses involved in cerebral malaria pathogenesis. Infect. Immun., 75, 2275-2282.

Nitcheu, J., Bonduelle, O., Combadiere, C., Tefit, M., Seilhean, D., Mazier, D. \& Combadiere, B. (2003) Perforin-dependent brain-infiltrating cytotoxic CD $8+\mathrm{T}$ lymphocytes mediate experimental cerebral malaria pathogenesis. J. Immunol., 170, 2221-2228.

Pais, T.F. \& Chatterjee, S. (2005) Brain macrophage activation in murine cerebral malaria precedes accumulation of leukocytes and CD8+ T cell proliferation. J. Neuroimmunol., 163, 73-83. 
Parroche, P., Lauw, F.N., Goutagny, N., Latz, E., Monks, B.G., Visintin, A., Halmen, K.A., Lamphier, M., Olivier, M., Bartholomeu, D.C., Gazzinelli, R.T. \& Golenbock, D.T. (2007) Malaria hemozoin is immunologically inert but radically enhances innate responses by presenting malaria DNA to Tolllike receptor 9. Proc. Natl. Acad. Sci. USA, 104, 1919-1924.

Rey, J., Buffet, P.A., Ciceron, L., Milon, G., Mercereau-Puijalon, O. \& Safeukui, I. (2014) Reduced erythrocyte deformability associated with hypoargininemia during Plasmodium falciparum malaria. Sci. Rep., 4, 3767.

Rodriguez, P.C., Zea, A.H., Culotta, K.S., Zabaleta, J., Ochoa, J.B. \& Ochoa, A.C. (2002) Regulation of T cell receptor CD3zeta chain expression by L-arginine. J. Biol. Chem., 277, 2112321129.

Rodriguez, P.C., Zea, A.H., DeSalvo, J., Culotta, K.S., Zabaleta, J., Quiceno, D.G., Ochoa, J.B. \& Ochoa, A.C. (2003) L-arginine consumption by macrophages modulates the expression of CD3 zeta chain in T lymphocytes. J. Immunol., 171, 12321239.

Salvemini, D. \& Marino, M.H. (1998) Inducible nitric oxide synthase and inflammation. Expert Opin. Investig. Drugs, 7, 65-75.

Schofield, L. \& Grau, G.E. (2005) Immunological processes in malaria pathogenesis. Nat. Rev. Immunol., 5, 722-735.

Slade, S.J. \& Langhorne, J. (1989) Production of interferongamma during infection of mice with Plasmodium chabaudi chabaudi. Immunobiology, 179, 353-365.

Tapiero, H., Mathe, G., Couvreur, P. \& Tew, K.D. (2002) I. Arginine. Biomed. Pharmacother., 56, 439-445.

Totino, P.R., Daniel-Ribeiro, C.T., Corte-Real, S. \& de Fatima Ferreira-da-Cruz, M. (2008) Plasmodium falciparum: erythrocytic stages die by autophagic-like cell death under drug pressure. Exp. Parasitol., 118, 478-486.

Walther, M., Jeffries, D., Finney, O.C., Njie, M., Ebonyi, A., Deininger, S., Lawrence, E., Ngwa-Amambua, A., Jayasooriya, S., Cheeseman, I.H., Gomez-Escobar, N., Okebe, J., Conway, D.J. \& Riley, E.M. (2009) Distinct roles for FOXP3 and FOXP3 CD4 T cells in regulating cellular immunity to uncomplicated and severe Plasmodium falciparum malaria. PLoS Pathog., 5, e1000364.

Walton, E., Oliveros, H. \& Villamor, E. (2014) Hemoglobin concentration and parasitemia on hospital admission predict risk of multiple organ dysfunction syndrome among adults with malaria. Am. J. Trop. Med. Hyg., 91, 50-53.

Wang, Q.H., Liu, Y.J., Liu, J., Chen, G., Zheng, W., Wang, J.C. \& Cao, Y.M. (2009) Plasmodium yoelii: assessment of production and role of nitric oxide during the early stages of infection in susceptible and resistant mice. Exp. Parasitol., 121, 268-273.

World Health Organization (WHO) (2013) World Malaria Report 2013.

http://www.who.int/malaria/publications/world_malaria report 2013/report/en/

[Accessed: April 15, 2015].

Wu, J.J., Chen, G., Liu, J., Wang, T., Zheng, W. \& Cao, Y.M. (2010) Natural regulatory T cells mediate the development of cerebral malaria by modifying the pro-inflammatory response.
Parasitol. Int., 59, 232-241.

Yanez, D.M., Batchelder, J., van der Heyde, H.C., Manning, D.D. \& Weidanz, W.P. (1999) Gamma delta T-cell function in pathogenesis of cerebral malaria in mice infected with Plasmodium berghei ANKA. Infect. Immun., 67, 446-448.

Yeo, T.W., Lampah, D.A., Gitawati, R., Tjitra, E., Kenangalem, E., McNeil, Y.R., Darcy, C.J., Granger, D.L., Weinberg, J.B., Lopansri, B.K., Price, R.N., Duffull, S.B., Celermajer, D.S. \& Anstey, N.M. (2007) Impaired nitric oxide bioavailability and L-arginine reversible endothelial dysfunction in adults with falciparum malaria. J. Exp. Med., 204, 2693-2704.

Yeo, T.W., Lampah, D.A., Gitawati, R., Tjitra, E., Kenangalem, E., McNeil, Y.R., Darcy, C.J., Granger, D.L., Weinberg, J.B., Lopansri, B.K., Price, R.N., Duffull, S.B., Celermajer, D.S. \& Anstey, N.M. (2008a) Recovery of endothelial function in severe falciparum malaria: relationship with improvement in plasma L-arginine and blood lactate concentrations. J. Infect. Dis., 198, 602-608.

Yeo, T.W., Rooslamiati, I., Gitawati, R., Tjitra, E., Lampah, D.A., Kenangalem, E., McNeil, Y.R., Price, R.N., Anstey, N.M. \& Duffull, S.B. (2008b) Pharmacokinetics of L-arginine in adults with moderately severe malaria. Antimicrob. Agents Chemother., 52, 4381-4387.

Yeramian, A., Martin, L., Arpa, L., Bertran, J., Soler, C., McLeod, C., Modolell, M., Palacin, M., Lloberas, J. \& Celada, A. (2006) Macrophages require distinct arginine catabolism and transport systems for proliferation and for activation. Eur. J. Immunol., 36, 1516-1526.

Zea, A.H., Rodriguez, P.C., Atkins, M.B., Hernandez, C., Signoretti, S., Zabaleta, J., McDermott, D., Quiceno, D., Youmans, A., O’Neill, A., Mier, J. \& Ochoa, A.C. (2005) Arginase-producing myeloid suppressor cells in renal cell carcinoma patients: a mechanism of tumor evasion. Cancer Res., 65, 3044-3048.

Zea, A.H., Rodriguez, P.C., Culotta, K.S., Hernandez, C.P., DeSalvo, J., Ochoa, J.B., Park, H.J., Zabaleta, J. \& Ochoa, A.C. (2004) L-Arginine modulates CD3zeta expression and T cell function in activated human $\mathrm{T}$ lymphocytes. Cell. Immunol., 232, 21-31.

Zheng, W., Wang, Q.H., Feng, H., Liu, J., Meng, H.R. \& Cao, Y.M. (2009) CD4+CD25+Foxp3+ regulatory T cells prevent the development of Th1 immune response by inhibition of dendritic cell function during the early stage of Plasmodium yoelii infection in susceptible BALB/c mice. Folia Parasitol. (Praha), 56, 242-250.

Zhu, J., Krishnegowda, G. \& Gowda, D.C. (2005) Induction of proinflammatory responses in macrophages by the glycosylphosphatidylinositols of Plasmodium falciparum: the requirement of extracellular signal-regulated kinase, p38, c-Jun N-terminal kinase and NF-kappaB pathways for the expression of proinflammatory cytokines and nitric oxide. $J$. Biol. Chem., 280, 8617-8627.

Zhu, X., Pan, Y., Li, Y., Cui, L. \& Cao, Y. (2012) Supplement of L-Arg improves protective immunity during early-stage Plasmodium yoelii 17XL infection. Parasite Immunol., 34, 412-420. 